\title{
Perspectivas na utilização de fitoterápicos na cicatrização tecidual: revisão sistemática
}

\author{
Perspectives in the use of herbal medicines in tissue healing: systematic review \\ Perspectivas en la utilización de fitoterápicos en la cicatrización del tejido: revisión sistemática \\ Anderson MARTELLI ${ }^{1}$ \\ Thiago Antonio Moretti de ANDRADE ${ }^{2}$ \\ Gláucia Maria Tech dos SANTOS ${ }^{3}$
}

\begin{abstract}
${ }^{I}$ Mestre; Programa de Pós graduação em Ciências Biomédicas - Centro Universitário Hermínio Ometto, FHO|Uniararas, Araras-SP; Especialista em Laboratório Clínico pela Faculdade de Ciências Médicas-UNICAMP, Campinas-SP

${ }^{2}$ Doutor; Docente do Programa de Pós-Graduação em Ciências Biomédicas, Centro Universitário Hermínio Ometto, FHO|Uniararas, Araras-SP

${ }^{3}$ Doutora; Docente do Programa de Pós-Graduação em Ciências Biomédicas, Centro Universitário Hermínio Ometto, FHO|Uniararas, Araras-SP
\end{abstract}

\begin{abstract}
Resumo
A cicatrização de feridas é uma resposta biológica à lesão tecidual. Inúmeras pesquisas e diversos métodos estão sendo desenvolvidos e empregados para acelerar o processo de cicatrização. A utilização de fitoterápicos tem merecido crescente interesse, assim, a presente revisão faz uma descrição das perspectivas na utilização de fitoterápicos na cicatrização tecidual. A pesquisa foi realizada a partir de uma revisão da literatura especializada, sendo consultados artigos científicos publicados entre os anos de 1996 e 2016. Empresas e pesquisadores de diferentes áreas do conhecimento e a população em geral têm demonstrado interesse nos fitoterápicos como alternativas para o tratamento de diversas afecções e lesões. Este fato ocorre principalmente pelo menor custo e a possibilidade de menores efeitos adversos dos fitoterápicos em comparação aos medicamentos alopáticos, assim como, pela biodiversidade da flora brasileira.
\end{abstract}

Descritores: Medicamentos Fitoterápicos; Cicatrização; Ferimentos e Lesões.

\begin{abstract}
Wound healing is a biological response to tissue injury. Numerous researches and various methods are being developed and used to accelerate the healing process. The use of herbal medicine has received increasing interest, so this review is a description of the prospects in the use of herbal medicines in tissue healing. The survey was conducted from a review of the literature, consulted with scientific articles published between 1996 and 2016. Companies and researchers from different areas of knowledge and the general population have shown interest in herbal remedies as alternatives to treat various diseases and injuries. This occurs mainly due to the lower cost and the possibility of minor adverse effects of herbal medicines compared to allopathic medicines, as well as the biodiversity of the Brazilian flora.

Descriptors: Phytotherapeutic Drugs; Wound Healing; Wounds and Injuries.

\section{Resumen}

La cicatrización de las heridas es una respuesta biológica a la lesión del tejido. Numerosas investigaciones y diversos métodos están siendo desarrollados y empleados para acelerar el proceso de cicatrización. La utilización de fitoterápicos ha merecido creciente interés, así, la presente revisión hace una descripción de las perspectivas en la utilización de fitoterápicos en la cicatrización del tejido. La investigación fue realizada a partir de una revisión de la literatura especializada, siendo consultados artículos científicos publicados entre los años 1996 y 2016. Empresas e investigadores de diferentes áreas del conocimiento y la población en general han demostrado interés en los fitoterápicos como alternativas para el tratamiento de diversas afecciones y lesiones. Este hecho ocurre principalmente por el menor costo y la posibilidad de menores efectos adversos de los fitoterápicos en comparación a los medicamentos alopáticos, así como por la biodiversidad de la flora brasileña.
\end{abstract}

Descriptores: Medicamentos Fitoterápicos; Cicatrización de Heridas; Heridas y Lesiones.

\section{INTRODUÇÃO}

Desde os primórdios da humanidade tem-se o conhecimento da utilização de plantas com finalidades terapêuticas ${ }^{1}$. A utilização de plantas medicinais na obtenção de substâncias fitoterápicas pode ser entendida como uma prática que atravessa milênios, estando historicamente presente na sabedoria do senso comum, articulando a cultura de gerações passadas e atuais e a saúde, uma vez que estes aspectos não ocorrem isoladamente, mas estão inseridos em um contexto histórico ${ }^{2}$. Ao longo dos séculos, substâncias de origem vegetal constituíram as bases para o tratamento de um número variado de doenças, quer de forma tradicional pelo conhecimento das propriedades de determinada planta, que é passado de geração a geração, quer pela utilização de espécies vegetais, como fonte de moléculas ativas ${ }^{3}$.

Atualmente o uso de fitoterápicos ocorre por todo o mundo e no Brasil. Mello et al. ${ }^{4}$ destacam que essa prática vem da miscigenação cultural envolvendo africanos, europeus e indígenas. Por essa razão a cultura brasileira é tão diversa, e para muitas comunidades brasileiras o uso de fitoterápicos é o único recurso terapêutico disponível. Dentre as principais razões que impulsionam o grande crescimento do mercado mundial de fitoterápicos a cada ano destaca-se a valorização de hábitos de vida mais saudáveis e, consequentemente, o consumo de produtos naturais; os evidentes efeitos colaterais dos medicamentos sintéticos; a descoberta de novos princípios ativos de plantas e a comprovação científica de suas atividades terapêuticas ${ }^{5}$. Devido ao fato do Brasil ser detentor de vasta biodiversidade tanto faunística como florística, além de grande variedade étnica e cultural, a população brasileira, principalmente a residente em zonas rurais, utiliza comumente o seu conhecimento empírico acerca do potencial terapêutico de plantas medicinais ${ }^{6,7}$.

Neste sentido, um estudo etnobotânico e etnofarmacológico realizado por Ferrão et al. $^{8}$ no município de Buritis, região Noroeste de Minas Gerais, com 393 indivíduos entrevistados revelou que $359(91 \%)$ faziam uso de plantas para tratamento de alguma enfermidade e/ou possuiam conhecimentos 
acerca das mesmas. Os autores observaram também que a parte da população entrevistada que mais detinha o conhecimento sobre as plantas medicinais encontrava-se acima de 60 anos (100\% dos indivíduos nessa faixa afirmaram possuir conhecimento acerca de plantas medicinais). O percentual de conhecimento diminuia gradativamente com a redução da faixa etária dos indivíduos. Assim, à medida que idosos vão desaparecendo, verdadeiros arquivos deixam de existir?

Inúmeras plantas com poder medicinal são empregadas no tratamento de diferentes enfermidades ${ }^{10}$, dentre elas, a cicatrização de feridas. No processo de cicatrização de feridas, o uso de plantas medicinais é mencionado desde a pré-história, quando eram utilizadas na forma de cataplasmas, com o intuito de estagnar hemorragias e favorecer o reparo tecidual, sendo muitas dessas plantas ingeridas, para atuação em via sistêmica ${ }^{11}$. Paradoxalmente, é possível encontrar no Brasil um grande número de pessoas que não possuem acesso ao tratamento convencional e muitas vezes essas lesões podem promover alterações funcionais importantes.

Revisão sistemática realizada por Piriz et al. ${ }^{12}$ selecionou 57 artigos que incluíam 46 estudos científicos com plantas medicinais e 11 pesquisas de alta relevância científica por seus benefícios para o conhecimento do potencial de plantas nativas brasileiras. Por esses dados é possível observar o crescente número de pesquisas utilizando algum tipo de fitoterápico. Dentre as plantas de interesse na Medicina Veterinária, o barbatimão ocupa posição de destaque por suas propriedades terapêuticas, como o efeito cicatrizante de feridas cutâneas. A casca dessa árvore é a principal matéria-prima para a formulação do fitoterápico e o medicamento já foi empregado em vários estudos na apresentação farmacológica de extratos fluídos ${ }^{13,14}$.

Apesar da importância dos fitoterápicos, o fato de sua utilização ser geralmente de forma empírica e as preparações, muitas vezes, não seguirem padrões rígidos de controle de qualidade, alguns protocolos terapêuticos envolvendo plantas medicinais podem resultar em efeitos adversos ao paciente $^{15}$. O uso imprudente, muitas vezes até para finalidades diferentes daquelas tradicionalmente empregadas, sua identificação errônea, a presença de adulterantes e contaminantes, as associações e sinergismos possíveis, assim como a obtenção ou preparo indevidos podem causar sérios problemas de saúde pública. Logo, é importante evitar a automedicação ou o uso indiscriminado, uma vez que o emprego de plantas medicinais ou mesmo de medicamentos fitoterápicos não significa ausência total de efeitos colaterais e de reações adversas ou tóxicas ${ }^{16}$.
Considerando-se que a cicatrização é um processo complexo, que começou a ser entendido em maior amplitude nos últimos anos, e que a utilização de plantas medicinais, por se tratar de tratamento pouco dispendioso comparado aos fármacos sintéticos, se mostra acessível à população carente, o presente estudo teve como objetivo realizar uma revisão sistemática das perspectivas na utilização de fitoterápicos na cicatrização tecidual.

\section{MATERIAL E MÉTODO}

Para a composição da presente revisão foi realizada estratégia de busca de artigos utilizando-se as bases de dados Medline, Scielo, Lilacs, Portal de Periódicos da Coordenação de Aperfeiçoamento de Pessoal de Nível Superior (CAPES) e a busca de dados no Google Acadêmico de artigos científicos por meio da combinação dos descritores "Medicamentos Fitoterápicos" ou "Cicatrização" ou "Ferimentos e Lesões" e seus correspondentes em inglês. Adicionalmente acrescentou-se a consulta de livros acadêmicos para complementação das informações sobre a utilização de fitoterápicos no processo de cicatrização.

Para seleção do material obedeceu-se a três etapas. A primeira foi caracterizada pela busca entre os meses de junho a dezembro de 2017 com a seleção de 58 artigos científicos. A segunda compreendeu a leitura dos títulos e resumos, visando uma maior aproximação e conhecimento, sendo excluídos os que não tivessem relação e relevância com o tema. Na terceira etapa, buscaram-se os textos que se encontravam disponíveis na íntegra, sendo estes, incluídos na revisão, os quais constituíram ensaios clínicos, artigos originais, revisões e revisões sistemáticas da literatura. Como critérios de elegibilidade e inclusão dos artigos, analisaram-se a procedência da revista e indexação, estudos que apresentassem dados referentes à utilização dos fitoterápicos no processo de cicatrização publicados entre os anos de 1996 e 2016. Na leitura e avaliação, os artigos que apresentaram os critérios de elegibilidade foram selecionados e incluídos na pesquisa por consenso. Como critério de exclusão utilizou-se referência incompleta e informações presentemente desacreditadas.

\section{RESULTADOS E DISCUSSÃO}

O objetivo deste estudo foi por meio de investigação focada, apresentar e discutir os achados da literatura referentes à utilização de medicamentos fitoterápicos para promoção da cicatrização tecidual, identificando, selecionando, avaliando e sintetizando evidências relevantes disponíveis. Neste contexto, os artigos foram lidos e criteriosamente agrupados na categoria fitoterápicos e cicatrização tecidual. A estratégia de busca, depois de aplicados os critérios de inclusão/exclusão, resultou em um total de 32 
artigos para compor esta revisão (Tabela 1).

Tabela 1. Estudos eleitos para a revisão sistemática

\begin{tabular}{|c|c|c|}
\hline Autoria & Ano & Tipo de Estudo \\
\hline Maciel et al. ${ }^{1}$ & 2002 & Atualização \\
\hline Silva et al. ${ }^{6}$ & 2010 & Experimental \\
\hline Rodriguez et al. ${ }^{11}$ & 2013 & Revisão \\
\hline Piriz et al. ${ }^{12}$ & 2014 & Experimental \\
\hline Silva et al. ${ }^{13}$ & 2009 & Experimental \\
\hline Carvalho et al. ${ }^{17}$ & 2007 & Atualização \\
\hline Mendonça et al. ${ }^{18}$ & 2009 & Experimental \\
\hline Lima et al..$^{19}$ & 2012 & Revisão \\
\hline Martelli et al. ${ }^{20}$ & 2016 & Revisão \\
\hline Isaac et al. ${ }^{21}$ & 2010 & Atualização \\
\hline Rodrigues $^{22}$ & 1996 & Revisão \\
\hline Barata-Silva et al..$^{23}$ & 2005 & Atualização \\
\hline Pereira et al. ${ }^{24}$ & 2014 & Atualização \\
\hline Dutra et al. ${ }^{25}$ & 2016 & Atualização \\
\hline Lima et al. ${ }^{26}$ & 2010 & Revisão \\
\hline Moura $^{27}$ & 2011 & Atualização \\
\hline Cabral Filho ${ }^{28}$ & 2004 & Experimental \\
\hline Queiroz et al. ${ }^{29}$ & 2002 & Experimental \\
\hline Hernandes et al. ${ }^{30}$ & 2010 & Experimental \\
\hline Maenthaisong et al. ${ }^{31}$ & 2007 & Revisão \\
\hline Soares et al. ${ }^{32}$ & 2013 & Experimental \\
\hline Spandre et al. ${ }^{33}$ & 2012 & Experimental \\
\hline Kulchetscki et al. ${ }^{34}$ & 2006 & Experimental \\
\hline Souza $^{35}$ & 2010 & Experimental \\
\hline Nitz et al. ${ }^{36}$ & 2006 & Experimental \\
\hline Fernandes et al. ${ }^{37}$ & 2014 & Experimental \\
\hline Silva et al. ${ }^{38}$ & 2013 & Experimental \\
\hline Montes et al. ${ }^{39}$ & 2009 & Revisão \\
\hline Santos et al. ${ }^{40}$ & 2014 & Experimental \\
\hline Carneiro et al. ${ }^{41}$ & 2014 & Atualização \\
\hline Santos et al. ${ }^{42}$ & 2011 & Atualização \\
\hline Colet et al. ${ }^{43}$ & 2015 & Experimental \\
\hline
\end{tabular}

$\mathrm{O}$ termo fitoterapia foi dado à terapêutica que utiliza os medicamentos cujos constituintes ativos são plantas ou derivados vegetais, e que tem a sua origem no conhecimento e no uso popular. Apesar dos avanços da medicina moderna no mundo, a Organização Mundial da Saúde reconhece que a maioria da população de países em desenvolvimento depende da medicina tradicional, já que $80 \%$ desta população desenvolvem práticas tradicionais em seus cuidados básicos na saúde, sendo $85 \%$ dessas representadas pelo uso de plantas medicinais ${ }^{17}$.

O mecanismo de cicatrização e/ou regeneração tecidual de uma lesão é um complexo processo biológico que envolve uma cascata perfeita e coordenada de células e eventos moleculares que visa promover a reconstituição de tecidos lesionados ${ }^{18,19,20}$. Este processo surge como uma resposta do tecido a lesões induzidas por traumas ou por procedimentos cirúrgicos e é caracterizado por três fases que se sobrepõem e apresentam característica especificas sendo elas a fase inflamatória, fase proliferativa e fase de remodelação ${ }^{21}$. Durante a fase inflamatória ocorrem hemostasia, migração de leucócitos e o início da cascata de reparação tecidual. A fase proliferativa se caracteriza por fibroplasia, angiogênese e reepitelização. Na fase de remodelação, o colágeno é o principal componente da derme, sendo que nesta etapa ocorre a mudança do tipo de colágeno que a compõe onde a disposição do colágeno tipo III é inicialmente mais abundante que o tipo I e ao longo deste processo, este vai sendo degradado ativamente enquanto que o colágeno I vai tendo sua produção aumentada pelos fibroblastos ${ }^{21}$.

Diversas são as plantas medicinais nativas da flora brasileira conhecidas pela etnofarmacologia e por apresentarem propriedades antimicrobianas e que, ao mesmo tempo, preenchem critérios de preservação ambiental e manejo auto-sustentável tais como: Anacardium occidentale (cajueiro), Pterodone marginatus (sucupira), Copaifera langsdorffii (copaíba), Anadenanthera colubrina (angico), Myroxylon peruiferum (bálsamo-do-peru), Stryphnodendron adstringens (barbatimão), Bixa orellana (urucum), Eugenia uniflora (pitanga), Psidium guajava (goiabeira), Mimosa tenuiflora (tepezcuite), Ilex paraguariensis (erva-mate), Ocotea odorifera (sassafrás), Hymenaea courbaril (jatobá), Schinus terebinthifolia (aroeira), Genipa americana (jenipapo), Tabebuia avellanedae (ipê-roxo) e Casearia sylvestris (guaçatonga) ${ }^{22}$.

$\mathrm{O}$ estudo dos fitoterápicos é extremamente complexo, pois diante da grande variedade de plantas com propriedades terapêuticas, muito ainda se tem a descobrir sobre os princípios ativos, isolamento, mecanismo de ação e efeitos colaterais ${ }^{1}$.

Muitas pesquisas que envolvem fitoterápicos são desenvolvidas em decorrência de informações terapêuticas obtidas do conhecimento da medicina popular. Um estudo realizado por Barata-Silva et al. ${ }^{23}$ com o objetivo de resgatar os conhecimentos sobre o uso de plantas com potencial medicinal, baseados em levantamentos etnobotânicos em populações tradicionais no estado do Rio Grande do Sul, verificou que 36 espécies de porte arbóreo são utilizadas comumente. Há um predomínio da utilização das folhas $(83 \%)$, em relação as demais partes da planta, principalmente por se tratar de espécies arbóreas.

Pereira et al. ${ }^{24}$ realizaram uma pesquisa de campo com 392 agricultores da zona rural da cidade de Jardim, localizada ao Sul do Ceará, na região do Cariri sobre o potencial terapêutico de Myracrodruon urundeuva conhecida popularmente como aroeira do sertão. É uma espécie nativa ameaçada de extinção que ocorre tanto na caatinga, como na floresta pluvial. Como resultado, 32\% (125) declararam nunca ter usado produtos de "aroeira", apesar de ter conhecimento de suas propriedades medicinais. Dos $68 \%$ (267) que usaram os produtos da "aroeira", a grande maioria afirmou ter obtido melhora na cicatrização, infecção de pele e outras patologias.

Dutra et al. ${ }^{25}$ apontam que nos últimos 28 anos (entre os anos de 1987 e 2015), cientistas brasileiros publicaram 34.614 artigos sobre as plantas medicinais. Entre 2011 e 2013 foram publicados mais de 10.000 artigos científicos sobre o tema.

É possível observar no contexto brasileiro que as pesquisas com plantas medicinais 
apresentaram avanços significativos nas últimas décadas. Piriz et al. ${ }^{12}$ em estudo de revisão relatam que foram estudados, experimentalmente ou clinicamente, quanto aos seus efeitos no auxílio do processo de cicatrização, 52 plantas medicinais e um composto de ervas. Em 46 espécies observou-se potencial elevado de cicatrização de feridas em ao menos um estudo, totalizando $88,5 \%$ podendo ser utilizadas como terapia em processos de cura de feridas e processos inflamatórios.

Desta forma é possível observar um numero significativo de espécies de plantas utilizadas no processo cicatricial de lesões. Lima et al. $^{26}$, considerando os efeitos medicinais do barbatimão, atribuem seus efeitos cicatrizantes ao elevado teor de taninos em sua composição química, podendo atingir níveis de $20 \%$ a $50 \%$. Este é utilizado principalmente na forma de extrato aquoso ou glicólico ${ }^{13,27}$.

O papel biológico dos taninos nas plantas tem sido alvo de diversos estudos principalmente nas interações ecológicas entre vegetais e herbívoros. Pesquisas sobre atividade biológica dos taninos evidenciaram importante ação contra microrganismos $^{28}$, além da ação antiinflamatória e cicatrizantes $^{29}$.

No processo cicatricial de feridas cutâneas, os taninos têm a capacidade de formar pontes de hidrogênio ou ligações hidrofóbicas duradouras com proteínas, polissacarídeos ou ambos. Com isso, ocorre a formação do complexo tanino proteína ou tanino-polissacarídeo, que por serem insolúveis em água formam uma camada protetora ou crosta sobre a lesão, permitindo que abaixo dessa camada o processo de cicatrização ocorra naturalmente. Esta capacidade de precipitação de proteínas também favorece a hemostasia após a injúria ${ }^{26}$.

$\mathrm{O}$ barbatimão também estimula à proliferação de queratinócitos na região lesionada, o que poderia facilitar a reepitelização da ferida ${ }^{10}$. Hernandes et al. $^{30}$ utilizaram uma pomada a base da fração semipurificada do extrato da casca da árvore de barbatimão (taninos condensados), na concentração de $1 \%$, em feridas cutâneas excisionais de ratos sendo observado que a pomada exerceu um efeito trófico sobre a proliferação de queratinócitos ao longo da margem de reepitelização em relação ao grupo controle.

Outra planta muito estudada e usada no processo de cicatrização de tecido cutâneo é a babosa, cientificamente denominada Aloe vera. É uma planta tropical da família Liliaceae que se desenvolve mais facilmente em climas quentes e $\operatorname{secos}^{31}$. Soares et al. ${ }^{32}$ analisaram o processo cicatricial de lesões em ratos Wistar utilizando Aloe vera e pau-ferro (Caesalpinia ferrea) em lesões de pele provocadas experimentalmente. Nos animais tratados com babosa, foi observada a presença de crosta fibrinoleucocitária desprendida do epitélio, presença de neovascularização e discreto infiltrado inflamatório. No grupo tratado com pau-ferro, os autores observaram grande quantidade de neovasos, presença de discreta crosta fibrinoleucocitária e de infiltrado leucocitário, sendo que o pau-ferro nos 5 primeiros dias da lesão apresentou melhores resultados, mas ambos apresentaram atividades cicatrizantes.

A literatura traz como fitoterápico cicatrizante a Casearia sylvestris conhecida popularmente como guaçatonga, uma árvore nativa do México, América Central e da América do Sul, com grande importância ecológica, farmacológica e comercial $^{33}$. Kulchetscki et al. ${ }^{34}$ relataram que uma lesão necrótica proliferativa, com secreção da mucosa de aspecto sanguinolento e purulento, localizada na região podal do membro anterior esquerdo de um cão tratada com extrato aquoso de $C$. sylvestris, após 12 dias ocorreu o desaparecimento de tecido necrótico sendo que o ferimento aparentava um início de restituição celular. Com dois meses de tratamento foi constatada cura significativa do ferimento com reconstituição quase total de todas as camadas dos diferentes tecidos celulares.

Souza ${ }^{35}$ realizou a indução de ferimentos em ratas Wistar com 60 dias e tratou com solução hidroalcoolica por via oral e topicamente com o extrato glicólico da $C$. sylvestris. Os animais tratados apresentaram uma resposta imediata e duradoura de células envolvidas na fase inflamatória, neutrófilos e macrófagos, redução do edema, estimulação da angiogênese, além da síntese e deposito de colágeno.

Nitz et al. ${ }^{36}$ utilizando extrato aquosos das plantas Coronopus didymus e Calendula officinalis em 15 ratos Wistar, machos, submetidos a lesões excisionais observou que o subgrupo tratado com $C$. didymus apresentou o maior número de fibroblastos $\mathrm{e}$ fibras colágenas em relação ao subgrupo $C$. officinalis e grupo controle. Os autores retratam que o uso tópico do extrato aquoso de $C$. didymus é eficiente no processo de cicatrização de feridas cutâneas em ratos Wistar.

Fernandes et al. ${ }^{37}$ utilizaram uma pomada a base de Bellis perenis, C. officinalis e Myristica sebifera como um auxiliar na cicatrização de lesões cutâneas induzidas em ratos, em comparação com solução fisiológica. Observaram uma cicatrização mais eficiente com a utilização da pomada.

Silva et al. ${ }^{38}$ avaliaram histologicamente os efeitos da aplicação tópica de géis contendo Anacardium occidentale Linn pertencente à família Anacardiaceae, e conhecida popularmente como cajueiro e Lippia sidoides Cham, da família Verbenaceae, conhecida como alecrim-pimenta no processo de cicatrização em dorso de ratos, comparando-os com gel placebo e gel de digluconato 
de clorexidina a 2\%. Ao final dos períodos experimentais observou-se que o dado de maior relevância no estudo foi a melhor cicatrização dos grupos contendo fitoterápicos no período de sete dias.

Silva et al. ${ }^{6}$ conduziram estudos experimentais utilizando ratos da linhagem Wistar, machos, com idade de 120 dias, que após incisão cirúrgica foram tratados com extrato de Pfaffia glomerata espécie pertencente à família Amaranthaceae, conhecida como fafia, corangosempre-viva e ginseng brasileiro. Foi observado que a contração da ferida no grupo tratado com Pfaffia glomerata apresentou resultados superiores ao controle. Com relação à análise histológica houve presença de processo inflamatório nos grupos estudados, sendo que ao final somente o grupo controle apresentou maior número de casos inflamatórios. Quanto à densidade vascular, ela foi superior no grupo tratado no período de uma semana. Uma revisão sistemática realizada por Montes $^{39}$ sobre as evidências para o uso do óleoresina de copaíba na cicatrização de ferida descreveu inúmeros estudos mostrando, entre tantas atividades já comprovadas cientificamente, um poder antiinflamatório, bactericida, antitumoral e cicatrizante da copaíba, sendo necessários estudos complementares a respeito de seus efeitos adversos e possível ação citotóxica.

Santos et al. ${ }^{40}$ avaliaram o processo de reparo tecidual de feridas cutâneas abertas de ratos tratadas com extrato aquoso de urucum - Bixa orellana contendo $2,5 \%$ de norbixina, produto da saponificação da bixina, carotenoide encontrado na resina da semente. Observaram um aumento significativo do infiltrado inflamatório, inicialmente com predomínio de polimorfonucleares (neutrófilos e eosinófilos) e em seguida de mononucleares (macrófagos e linfócitos) - $3^{\circ}$ dia e a partir do $14^{\circ}$ dia pós-operatório respectivamente. Quanto à formação de novos vasos sanguíneos, encontrou-se aumento significativo e gradativo no grupo tratado após o $7^{\circ}$ dia de pós-operatório. Os autores observaram ao final do processo de reparo um aumento de cerca de $100 \%$ na média da densidade vascular quando comparado ao controle. Analisando a eficácia do tratamento no número de fibroblastos e na quantidade de deposição total de colágeno, verificaram que até o $14^{\circ}$ dia póscirúrgico ocorreu diminuição significativa de 50 a $60 \%$ na média do número de fibroblastos, sendo que, no $21^{\circ}$ dia de reparo houve aumento de cerca de 50\% na média da quantidade destas células. Embora o tratamento com a norbixina tenha ocasionado uma marcada variação na média da quantidade de fibroblastos nos diferentes períodos de reparo, a quantidade de colágeno depositada se manteve similar à observada no grupo controle.

Apesar do grande contingente de publicações com fitoterápicos em nível mundial, observa-se que o Brasil vem desenvolvendo pesquisas importantes para o avanço do conhecimento das propriedades medicinais das plantas utilizadas pela população ${ }^{12,41}$. Também existem programas e políticas que estimulam a inserção deste tipo de terapia no SUS, o que demonstra a busca pela oferta de um atendimento humanizado e integral ${ }^{12}$. O intuito deste trabalho não foi de exaurir e/ou retratar a função de todas as experiências nesta linha. Não obstante à crescente busca por integrativas medicamentosas, os estudos acerca da fitoterapia ainda são difíceis no Brasil, sendo necessário o desenvolvimento de pesquisas nesta área que enriquecerão o conhecimento dos profissionais da saúde, auxiliando e tornando mais seguras e eficazes a implementação das práticas fitoterápicas $^{41,42}$.

Os resultados descritos demonstram evidências científicas do uso de fitoterápicos no reparo tecidual e paradoxalmente a necessidade de se avançar de modo que a comunidade científica deva despertar o interesse e aprofundar estudos sobre a aplicabilidade clínica de nossa flora ${ }^{43}$. Espera-se que, o produto ou o resultado final seja direcionada para a saúde e bem-estar para a população brasileira ${ }^{12}$.

CONCLUSÃO

O reparo tecidual de ferimentos, por ser um evento sistêmico, abrange uma gama de fatores que precisam interagir entre si para que haja eficiência no processo. Temos que evoluir muito quanto à utilização e validação do potencial cicatrizante dos fitoterápicos. Pesquisas devem ser conduzidas de maneira criteriosa quanto à caracterização do produto fitoterápico utilizado, bem como o seu mecanismo de ação favorecendo dessa forma, um maior interesse de indústrias farmacêuticas para o desenvolvimento de produtos fitoterápicos com qualidade comprovada, servindo como incentivo para realização de mais estudos relacionados às plantas medicinais.

Acredita-se que o presente estudo se torna relevante e oportuno à medida que a incidência e prevalência de feridas vêm aumentando, com consequências sociais significativas sobre os portadores que podem desenvolver sequelas crônicas.

\section{REFERÊCIAS}

1. Maciel MAM, Pinto AC, Veiga Júnior VF. Plantas medicinais: a necessidade de estudos multidisciplinares. Quím Nova. 2002; 25(3):429-38.

2. Alvim NAT, Ferreira MA, Cabral IE, Almeida Filho AJ. O uso de plantas medicinais como recurso terapêutico: das influências da formação profissional às implicações éticas e legais de sua aplicabilidade como extensão da prática de cuidar realizada pela enfermeira. Rev LatinoAm Enfermagem. 2006; 14(3):316-23. 
3. Carvalho ACB, Silveira D. Drogas vegetais: uma antiga nova forma de utilização de plantas medicinais. Brasília Med. 2010; 48(2):219-37.

4. Melo JG. et al. Qualidade de produtos a base de plantas medicinais comercializados no Brasil: castanha-da-índia (Aesculus hippocastanum (L.), capim-limão (Cymbopogon citratus (DC.) Stapf e centela (Centella asiatica (L.) Urban). Acta Bot Bras. 2007; 21(1):27-36.

5. Secretaria Municipal de Saúde de Londrina. Protocolo de Fitoterapia. 3.ed. 2012.

6. Silva LAF, Silva JA, Lima CRO, Dambros CE, Cardoso VS. Uso popular do barbatimão. In: Silva LAF, Eurides D, Paula JR, Lima CRO, Moura MI. Manual do barbatimão. Goiânia: Kelps, 2010; p.79-85.

7. Corrêa VS, Cerdeira AL, Fachin AL, Bertoni BW, Pereira PS, França SC et al. Geographical variation and quality assessment of Stryphnodendron adstringens (Mart.) Coville within Brazil. Genet Resour Crop Evol. 2012; 59(7):1349-56.

8. Ferrão BH, Oliveira HB, Molinari RF, Teixeira MB, Fontes GG, Amaro MOF et al. Importância do conhecimento tradicional no uso de plantas medicinais em Buritis, MG, Brasil. Ciência e Natura. 2014; 36(Esp):321-34.

9. Costa FGC, Nunes FCP, Peres V. Mapeamento etnofarmacológico e etnobotânico de espécies de cerrado, na microrregião de Patos de Minas. Perquirere. 2010; 2(7):93-111.

10. Rodrigues DF, Mendes FF, Noronha Filho ADF, Silva JA, Silva LAF. O extrato da casca de barbatimão, Stryphnodendron adstringens (Martius) Coville, na cicatrização de feridas em animais. Enciclopédia Biosfera. 2013; 9(16):1583-1601.

11. Silva DM, Mocelin KR. O cuidado de enfermagem ao cliente portador de feridas sob a ótica do cuidado transcultural. Nursing. 2007; 9(105):8188.

12. Piriz MA, Lima CAB, Jardim VMR, Mesquita MK, Souza ADZ, Heck RM. Plantas medicinais no processo de cicatrização de feridas: uma revisão de literatura. Rev Bras Pl Med. 2014; 16(3):628-36.

13. Silva LAF, Moura MI, Persiano CB, Helou JB, Lima CRO, Freitas SLR, Almeida E, Silva J, Goulart DS, Castro LTS. Extrato da casca do barbatimão (Stryphnodendron barbatiman Martius) associado ao tratamento cirúrgico e toalete dos cascos na recuperação de bovinos da raça nelorecom dermatite digital. Ciência Animal Brasileira. 2009; Suppl1:373-78.

14. Barroso JEM, Ximenes FHB, Leite CR, Mustafa VS, Borges JRJ, Castro MB et al. Comparação entre os efeitos de diferentes tratamentos na cicatrização de pele por segunda intenção em ovinos. Acta Vet Bras. 2010; 4(4):298-302.

15. Turolla MSR, Nascimento ES. Informações toxicológicas de alguns fitoterápicos utilizados no Brasil. Rev Bras Ciênc Farm. 2006; 42(2):289-306.

16. Araújo EJF, Araújo DYML, Freitas RM, Ferreira PMP. Aspectos toxicológicos da planta medicinal Casearia sylvestris Swartz: revisão de literatura. Rev ciênc farm básica apl. 2014; 35(3):355-61.

17. Carvalho ACB, Nunes DSG, Baratelli TG, Shuqair NSMSAQ, Machado Netto E. Aspectos da legislação no controle dos medicamentosfitoterápicos. T \& C Amazônia. 2007; 5(11):26-32.

18. Mendonça FAS, Passarini Junior JR, Esquisatto MA, Mendonça JS, Franchini CC, Santos GM. Effects of the application of Aloe vera (L.) and microcurrent on the healing of wounds surgically induced in Wistar rats. Acta Cir Bras. 2009; 24(2):150-55.

19. Lima CRO, Rabelo RE, Moura VMBD, Silva LAF, Tresvenzol LMF. Cicatrização de feridas cutâneas e métodos de avaliação. Revisão de literatura. Rev CFMV. 2012; 56:53-9.

20. Martelli A, Theodoro V, Zaniboni VE, Freitas BA, Pastre GM, Melo KM et al. Microcorrente no processo de cicatrização: revisão da literatura. Arch Health Invest. 2016;5(3):134-39.

21. Isaac C, Ladeira PRS, Rego FMP, Aldunate JCB, Ferreira MC. Processo de cura das feridas: cicatrização fisiológica. Rev med (São Paulo). 2010; 89(3/4):125-31.

22. Rodrigues RR. Trilhas do parque da ESALQ. Árvores medicinais. Piracicaba: Escola Superior de Agricultura "Luiz de Queiroz" - USP; 1996.

23. Barata-Silva AW, Macedo RLG, Gomes JE. Potencial de utilização de espécies arbóreas medicinais no Rio Grande do Sul. Revista Científica Eletrônica de Engenharia Florestal 2005; ano III(6).

24. Pereira PS, et al. Uso da Myracroduon urundeuva Allemão (aroeira do sertão) pelos agricultores no tratamento de doenças. Rev cuba plantas med. 2014; 19(1):51-60.

25. Dutra RC, Campos MM, Santos AR, Calixto JB. Medicinal plants in Brazil: Pharmacological studies, drug discovery, challenges and perspectives. Pharmacol Res. 2016; 112:4-29.

26. Lima CRO, Souza LA, Helou JB, Almeida E, Silva J, Caetano LB. Caracterização dos metabólitos secundários do barbatimão. In: Silva LAF, Eurides D, Paula JR, Lima CRO, Moura MI. Manual do barbatimão. Goiânia: Kelps; 2010. p.61-68.

27. Moura MI. Enfermidades cutâneas digitais 
bovinas: aspectos genéticos e terapêuticos [tese]. Goiânia: Escola de Veterinária e Zootecnia UFGO; 2011.

28. Cabral Filho SLS. Efeito do teor de tanino do sorgo sobre a fermentação ruminal e parâmetros nutricionais dos ovinos [tese]. Piracicaba: Centro de Energia Nuclear na Agricultura USP; 2004.

29. Queiroz CRAA, Morais SAL, Nascimento EA. Caracterização dos taninos da aroeira-preta (Myracrodruon urundeuva). R Árvore, ViçosaMG. 2002; 26(4):485-92.

30. Hernandes L, Pereira LMS, Palazzo F, Mello JCP. Wound healing evaluation of ointment from Stryphnodendron adstringens (barbatimão) in rat skin. Braz J Pharm Sci. 2010; 46(3):431-36.

31. Maenthaisong R, Chayakunapruk N, Niruntraporn S, Kongkaew C. The efficacy of Aloe vera used for burn wound healing: a systematic review. Burns. 2007; 33(6):713-18.

32. Soares JA, Barros M, Gonçalez WP, Crisci AR, Jorge MHS. Avaliação da atividade cicatrizante da Caesalpinia férrea ex. TUL. Varferreae da Aloe vera (L.) Burm. em lesões cutâneas totais em ratos. Persp online: biol \& saúde. 2013; 11(3):33-42.

33. Spandre P, Zanette F, Biasi LA, Koheler HS, Niesing PC. Estaquia caulinar de guaçatonga (Casearia sylvestris Swartz) nas quatro estações do ano, com aplicação de diferentes concentrações de AIB. Rev Bras Pl Med. 2012; 14(3):529-36.

34. Kulchetscki 1, Quaquarelli CA, Lima PR. A guaçatonga (Casearia sylvestris sw.) e seu uso potencial como fitoterápico: um resultado prático de trabalho extensionista no distrito de Itaiacoca. Conexão UEPG. 2006; 2(1):16-22.

35. Souza APGF. Efeito da Guaçatonga e do laser In $\mathrm{GaP}$ nas diferentes fases do processo de cicatrização de feridas dérmicas [tese]. Viçosa: Programa de Pós-graduação em Bioquímica Agrícola-UFV; 2010.

36. Nitz AC, Ely JB, d'Acampora AJ, Tames DR, Corrêa BP. Estudo morfométrico no processo de cicatrização de feridas cutâneas em ratos, usando: Coronopus didymus e Calendula officinali. Arq Catar Med. 2006; 35(4):74-9.

37. Fernandes ES, Santos RA, Olieira BS, Meireles DS. Comparative analysis of the use of CMR pomade (Bellis perenis + Calendula officinalis + Myristica sebifera) and physiological solution in tissue scarring of rats (Rathus norvegicus). Sci Elec Arch. 2014; (7):103-7.

38. Silva FP, Aires PA, Praxedes Neto RAL, Aguiar WF, Costa FN, Viana FAC et al. Avaliação dos extratos de Anacardium occidentale Linn $e$
Lippia sidoides Cham no processo de cicatrização tecidual. Estudo histológico em dorso de ratos. Braz J Periodontol. 2013; 23(4):18-25.

39. Montes LV, Broseghini LP, Andreatta FS, Sant'Anna MES, Neves VM, Silva AG. Evidências para o uso da óleo-resina de copaíba na cicatrização de ferida - uma revisão sistemática. Natureza on line. 2009; 7(2): 61-7.

40. Santos JAA, Sousa MFAM, Silva ELV, Aguiar Júnior FCA. Avaliação histomorfométrica do efeito do extrato aquoso de urucum (norbixina) no processo de cicatrização de feridas cutâneas em ratos. Rev Bras P1 Med. 2014; 16(3):637-43.

41. Carneiro FM, Silva MJP, Borges LL, Albernaz LC, Costa JAP. Tendências dos estudos com plantas medicinais no Brasil Rev Sapiência. 2014; 3(2):44-75.

42. Santos RL, Guimaraes GP, Nobre MSC, Portela AS. Análise sobre a fitoterapia como prática integrativa no Sistema Único de Saúde. Rev bras plantas med. 2011; 13(4):486-91.

43. Colet C, Portella GZ, Spanevello S, Neu D, Dalpiaz J, Petri A et al. Uso de Aloe sp. no Município de Pejuçara - RS. UNOPAR Cient Ciênc Biol Saúde. 2015; 17(2):119-23.

\section{CONFLITO DE INTERESSES}

Os autores declaram não haver conflitos de interesse.

\section{AUTOR PARA CORRESPONDENCIA}

\section{Anderson Martelli}

martellibio@hotmail.com

Submetido em 18/05/2018

Aceito em 27/06/2018 